\title{
A Method for Simultaneous Measurement of Intragastric, Intraduodenal, and Intracolonic Pressures in the Bilaterally Vagotomized Spinal Rat
}

\author{
Y. N. Zhu, K. M. Dhasmana, and W. Erdmann \\ Department of Anaesthesiology, Faculty of Medicine and Health Sciences, Erasmus University Rotterdam, \\ the Netherlands
}

\begin{abstract}
A method has been developed where quantitative evaluation of intragastric (IGP), intraduodenal (IDP), and intracolonic (ICP) pressures $\left(\mathrm{cm} \mathrm{H}_{2} \mathrm{O}\right.$ ) can be obtained in the bilaterally vagotomized spinal rat. The preparation is very sensitive to 5 -hydroxytryptamine $(5-\mathrm{HT})$ and 5-HT-agonists, carbachol, histamine, dopamine, and/or noradrenaline. The effects of drugs on IGP, IDP, and ICP (increase or decrease) can be assessed and a dose-response curve before and after antagonists can be computed. The described experimental model is simple, reliable, reproducible, and appropriate to study and differentiate the different gastrointestinal system receptors that seem to be involved in the modulation of gastrointestinal motility. The additional advantage in using this method is that drug effects on the motility of stomach, duodenum, and colon can be investigated simultaneously.
\end{abstract}

Keywords: Gastrointestinal system; Intragastric (IGP), Introduodenal (IDP), and Intracolonic (ICP) pressures; Bilaterally vagotomized spinal rat; Drug effects on gastrointestinal motility; Agonists and antagonists in gastrointestinal motility.

\section{Introduction}

Gastrointestinal propulsion and motility is controlled by the extrinsic and enteric nervous system. The latter consists of two interconnected plexi (viz. Auerbach's and Meissner's plexus) which play an important role in the physiological regulation of gastrointestinal peristalsis. The extrinsic nerve fibers constitute parasympathetic and sympathetic innervation to the gastrointestinal system. The neurotransmitters in the extrinsic system, acetylcholine, and noradrenaline, but probably also dopamine (Orloff et al., 1985; Dhasmana et al., 1989) and 5-HT (Gershon and Erde, 1981) play an important modulating role in the gastrointestinal motility. Hence, in order to circumvent central and vagal influences on the gastrointestinal system, we

Address reprint requests to Dr. Y. H. Zhu, Department of Anaesthesiology, Faculty of Medicine and Health Sciences, Erasmus University Rotterdam, P.O. Box 1738, 3000 DR Rotterdam, The Netherlands.

Received January 1993; revised and accepted July 1993. have reported the measurement of IGP in the bilaterally vagotomized spinal rats (Dhasmana et al., 1992). Nevertheless, due to the pathophysiological complexity of the gastrointestinal system, our understanding about the mechanisms of actions of various drugs on the gastrointestinal system is rather limited. In view of this fact we have developed a simple method by which the role of different receptors of the gastrointestinal muscles is explored and the agonistic and antagonistic interaction on the gastrointestinal system analyzed. The purpose of the present study was to investigate the advantages and disadvantages of the newly developed method with the goal to get a true picture of the agonistic and antagonistic influence of the various drugs that have an impact on gastrointestinal motility.

\section{Materials and Methods}

\section{Preparation of the Model}

Wistar rats (250-350 g) of either sex were used in the present experiments. The animals were fasted for 
$24 \mathrm{hr}$ but allowed water ad libitum. All animals were anesthetized with halothane $(2 \%-3 \%)$ in nitrous oxide/ oxygen $(3: 2)$ and were paralyzed with pancuronium bromide $(90 \mu \mathrm{g} / \mathrm{kg}$ i.v.). Subsequently, artificial ventilation was performed via a tracheostomy with anesthesia continued as above.

Both common carotid arteries and the left external jugular vein were cannulated with a thin polyethylene catheter (outside diameter: $0.70 \mathrm{~mm}$; inside diameter: $0.50 \mathrm{~mm}$ ) for the recording of blood pressure and administration of drugs, respectively. The vagus nerves of both sides were separated from the common carotid artery sheath and cut through on both sides at the cervical level (C4/5). The abdominal cavity was opened; the distal end of the esophagus (cardiac), the pylorus, duodenum, and ascending colon were dissected free. A catheter (outside diameter: $2.67 \mathrm{~mm}$; inside diameter: $1.67 \mathrm{~mm}$ ) was brought into the stomach via the Inouth, a second catheter was introduced into the duodenum via the duodenal bulb, and a third was inserted into the ascending colon via the most proximal end of the colon (both with a $2-\mathrm{cm}$ long pouch). The catheters were secured with a ligation and were filled with 2.5(stomach), 1.5- (duodenum), and 1.5-ml (colon) warm saline $\left(20^{\circ}-25^{\circ} \mathrm{C}\right)$. Before filling the pouches of the duodenum and the colon, we flushed each catheter with saline to make it free from fecal material, thereafter the catheter holding pouches were closed from both sides with a silk thread. The stomach and intestine were pushed back into the abdominal cavity which was then closed with a suture to maintain the normal position of the abdomen (Figure 1).

The four catheters (blood pressure and the gastrointestinal pressures-IGP, IDP, ICP) were connected to four Statham transducers, and the pressures were amplified and recorded by a Grass Model 70 Polygraph. In this way continuous and simultaneous registration of mean arterial pressure (MAP mmHg), IGP, IDP, and ICP $\left(\mathrm{cm} \mathrm{H}_{2} \mathrm{O}\right)$ was achieved.

The rat was placed in a steriotaxic apparatus and a small transverse incision (about $0.5 \mathrm{~cm}$ long) was made on the back of the neck under the occipital protuberance onto the spinal column. In order to reach the atlanto-occipital membrane, we had to retract the dorsal neck musculature downwards below the third cervical vertebra. The atlanto-occipital membrane was opened by transverse incision, and pulsation of the cerebrospinal fluid could be now observed. With the help of a small aortic aneurism needle, the spinal cord was lifted up and cut at the level of the first cervical vertebra. In the following step the cranial cavity was filled with a gauge pushed through the opening until the brain was destroyed and total intracranial hemostasis achieved. The wound was closed by skin sutures, halothane and nitrous oxide were stopped after spinal sec- tion, and artificial ventilation was continued by oxygen and air (70:30) only.

The described method used and developed in our laboratory has been meanwhile used in 486 rat experiments with a failure rate of $10(2 \%)$ where either IGP, IDP, and/or ICP could not be measured or mean arterial pressure did not stabilize. Immediate autopsy in those discarded rats showed damage of the ileocolic (2), supraduodenal (2), and left gastric artery (2); in addition, one perforation of the colon and one obstruction of the intracolon catheter. In two other rats nonstabilization of the mean arterial pressure indicated an incomplete spinal section.

\section{Drug Investigation Procedure}

Sixty rat experiments were included in the present study. We allowed $1 \mathrm{hr}$ for stabilization of the physiological parameters after preparation was completed. All drugs were administered i.v. in the form of a bolus injection.

1. Six rats received a bolus of $5-\mathrm{HT} 2.5 \mu \mathrm{g} / \mathrm{kg}, 10 \mathrm{~min}$ later $5.0 \mu \mathrm{g} / \mathrm{kg}$, and $10 \mathrm{~min}$ thereafter $10 \mu \mathrm{g} / \mathrm{kg}$. Before each new injection IGP, IDP, and ICP had reached base line values again. Saline $(0.5 \mathrm{ml})$ was injected and after $10 \mathrm{~min}$ the same procedure with the three dosages of 5-HT was repeated as above. $\mathrm{Next}, 1.0 \mathrm{ml}$ of saline was injected, and later 2.0 $\mathrm{ml}$; each saline injection was again followed by the administration of the 5-HT series. These experiments served as control. In all of the following experiments the drug to be tested was preceded by the administration of 5-HT in three dosages. Thus a response to each new drug was compared to the 5-HT control group behavior.

2. In six rats gastrointestinal response to 5-MT (5methoxytryptamine) $(3,10$, and $30 \mu \mathrm{g} / \mathrm{kg})$ was tested.

3. 5-CT (5-carboxyamidotryptamine) in dosages of 25,50 , and $100 \mu \mathrm{g} / \mathrm{kg}$ was evaluated in an additional six rats.

4. In another six rats methiothepin was given in dosages of $0.1,0.3$, and $0.5 \mathrm{mg} / \mathrm{kg}$ before and after administration of 5 -HT $(2.5,5.0$, and $10 \mu \mathrm{g} / \mathrm{kg})$.

5. Then methiothepin (three dosages, see above) was given before and after 5-MT $(3,10$, and $30 \mu \mathrm{g} / \mathrm{kg})$,

6. In another series methiothepin (three dosages) was administered before and after 5-CT $(25,50$, and $100 \mu \mathrm{g} / \mathrm{kg}$ ).

7. a. 5-HT is given in three incremental dosages (see above), then carbachol $0.5 \mu \mathrm{g} / \mathrm{kg}$ is applied.

b. After the return of gastrointestinal pressures to base line values, atropin is given in dosages of $0.1,0.2,1.0$, and $2.0 \mathrm{mg} / \mathrm{kg}$ each time followed 
Figure 1. Three catheters were brought into the stomach, duodenum, and colon, respectively (for sites of insertion read methods). The arterial supply is induced to draw attention to the fact that due to the anatomical neighborhood of place of insertion and trunks of supplying vessels, the operative procedure might damage blood supply with the consequence of severe impairment of intestinal motility.

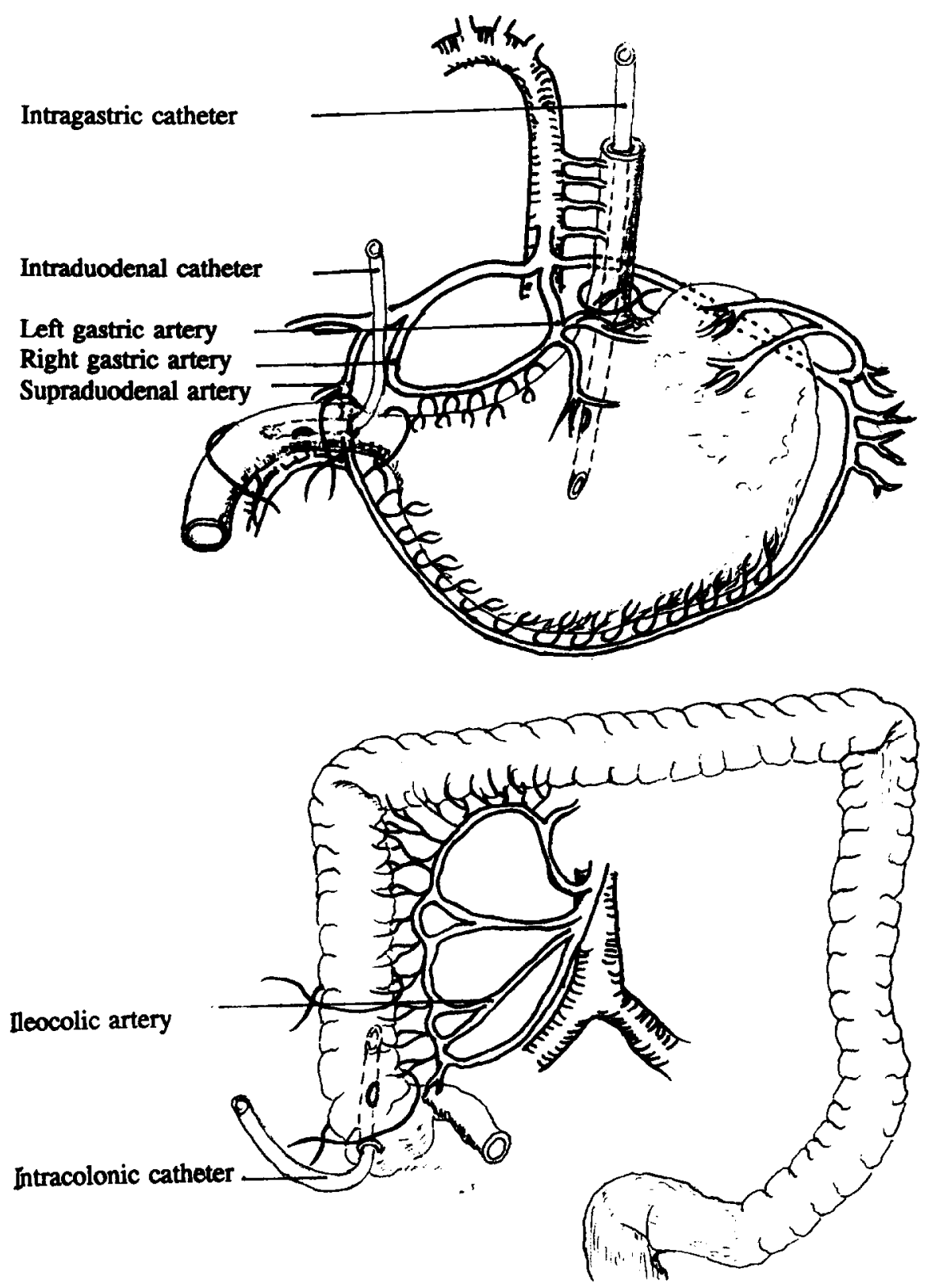

by another dosage of prazosin $0.1,0.3$, and $0.5 \mathrm{mg} /$ $\mathrm{kg}$, respectively.

All compounds were dissolved in physiological saline with a small amount of ascorbic acid added to prevent oxidation of the drugs.

\section{Data Presentation and Statistical Evaluation}

All the data in the table and illustrations are presented as means \pm SEM. Calculation of significance of the differences between the changes in IGP, IDP, and ICP before and after saline and various antagonists

10. Noradrenaline is given in incremental dosages of 1,3 , and $5 \mu \mathrm{g} / \mathrm{kg}$ repeatedly, each time followed 
Table 1. Effect of Saline on 5-Hydroxytryptamine Induced Increase in Intragastric, Intraduodenal, and Intracolonic Pressures in Bilaterally Vagotomized Spinal Rats

\begin{tabular}{rcccc}
\hline & & \multicolumn{3}{c}{ Saline $(\mathrm{ml} / \mathrm{kg}$ i.v. $)$} \\
\cline { 3 - 5 } 5-HT $(\mu \mathrm{g} / \mathrm{kg}$ i.v. $)$ & Control & Pressure & 1.0 & 2.0 \\
\hline & Intragastric & $\left(\mathrm{cm} \mathrm{H}{ }_{2} \mathrm{O}\right)$ & \\
2.5 & $1.82 \pm 0.35$ & $2.20 \pm 0.79$ & $2.16 \pm 0.70$ & $2.12 \pm 0.34$ \\
5.0 & $2.36 \pm 0.50$ & $2.62 \pm 0.40$ & $2.64 \pm 0.45$ & $2.70 \pm 0.37$ \\
10.0 & $4.12 \pm 0.92$ & $4.68 \pm 0.92$ & $4.16 \pm 0.56$ & $4.16 \pm 0.53$ \\
& Intraduodenal & Pressure & $\left(\mathrm{cm} \mathrm{H} \mathrm{H}_{2} \mathrm{O}\right)$ & \\
2.5 & $1.86 \pm 0.65$ & $1.86 \pm 0.74$ & $1.80 \pm 0.57$ & $1.98 \pm 0.54$ \\
5.0 & $2.74 \pm 0.95$ & $2.60 \pm 0.79$ & $2.46 \pm 0.75$ & $2.38 \pm 0.55$ \\
10.0 & $3.10 \pm 0.91$ & $3.10 \pm 0.87$ & $3.24 \pm 0.88$ & $3.22 \pm 0.72$ \\
& Intracolonic & Pressure & $\left(\mathrm{cm} \mathrm{H} \mathrm{H}_{2} \mathrm{O}\right)$ & \\
2.5 & $3.10 \pm 0.99$ & $3.40 \pm 1.20$ & $3.52 \pm 1.20$ & $3.20 \pm 1.0$ \\
5.0 & $3.92 \pm 1.30$ & $3.90 \pm 1.20$ & $3.82 \pm 1.20$ & $3.80 \pm 1.0$ \\
10.0 & $4.82 \pm 1.32$ & $4.70 \pm 1.50$ & $4.70 \pm 1.33$ & $5.00 \pm 1.23$ \\
\hline
\end{tabular}

was performed using Duncan's new multiple range test, in case an analysis of variance (randomized block design) had revealed that the samples represented different populations (Saxena, 1985). Statistical significance was accepted at $p<0.05$ (two tailed).

\section{Results}

5-HT, 5-CT, and 5-MT all induced an increase in gastrointestinal pressures and effect of physiological saline:

I.V. bolus injection of $5-\mathrm{HT}(2.5,5.0$, and $10 \mu \mathrm{g} / \mathrm{kg}$ i.v.) and the tested 5-HT agonists (5-MT 3, 10, and 30 $\mu \mathrm{g} / \mathrm{kg}$; 5 -CT 25,50 , and $100 \mu \mathrm{g} / \mathrm{kg}$ i.v.) showed a dosedependent increase in intragastrointestinal pressure in all segments (IGP, IDP, ICP) investigated. The onset of pressor response and the peak effect of all three drugs lay in-between $30 \mathrm{sec}$, was of short endurance (5-7 $\mathrm{min}$ ), and base line was always reached within 10 $\mathrm{min}$. Preadministration of saline $(0.5,1$, and $2 \mathrm{ml} / \mathrm{kg}$ i.v.) did not influence the pressor responses at all (Table 1, 2, and 3).

In conclusion, 5-HT and 5-HT-agonists in dosages chosen for these experiments showed reproducible dose-response effects, no signs of tachyphylaxis on repeated administration in short intervals $(10 \mathrm{~min})$ as well as no saline pretreatment effect.

Therefore, the above-mentioned doses were used in order to investigate the agonistic and antagonistic effects of various drugs.

Table 2. Effect of Saline on 5-Methoxytryptamine Induced Increase in Intragastric, Intraduodenal, and Intracolonic Pressures in Bilaterally Vagotomized Spinal Rats

\begin{tabular}{ccccc}
\hline & & \multicolumn{3}{c}{ Saline $(\mathrm{ml} / \mathrm{kg} \mathrm{i.v.})$} \\
\cline { 3 - 4 }$(\mu \mathrm{g} / \mathrm{kg} \mathrm{i.v.})$ & Control & & 1.0 & 2.0 \\
\hline & Intragastric & Pressure & $(\mathrm{cm} \mathrm{H})$ & \\
1.0 & $0.96 \pm 0.38$ & $1.60 \pm 0.50$ & $1.22 \pm 0.44$ & $1.50 \pm 0.37$ \\
3.0 & $1.40 \pm 0.32$ & $1.92 \pm 0.50$ & $1.66 \pm 0.40$ & $1.74 \pm 0.36$ \\
10.0 & $2.26 \pm 0.44$ & $2.08 \pm 0.42$ & $2.72 \pm 0.43$ & $2.36 \pm 0.42$ \\
30.0 & $3.36 \pm 6.41$ & $2.50 \pm 0.58$ & $2.84 \pm 0.54$ & $3.38 \pm 0.41$ \\
& Intraduodenal & Pressure & $\left(\mathrm{cm} \mathrm{H}_{2} \mathrm{O}\right)$ & \\
1.0 & $1.66 \pm 0.55$ & $1.48 \pm 0.27$ & $1.36 \pm 0.30$ & $1.50 \pm 0.26$ \\
3.0 & $2.38 \pm 0.68$ & $2.54 \pm 0.6$ & $1.90 \pm 0.34$ & $1.92 \pm 0.57$ \\
10.0 & $3.36 \pm 0.64$ & $3.34 \pm 0.81$ & $2.80 \pm 0.44$ & $3.60 \pm 0.84$ \\
30.0 & $3.26 \pm 1.14$ & $4.32 \pm 0.80$ & $3.64 \pm 0.78$ & $4.04 \pm 0.96$ \\
& Intracolonic & Pressure & $\left(\mathrm{cm} \mathrm{H}_{2} \mathrm{O}\right)$ & \\
1.0 & $1.40 \pm 0.29$ & $2.09 \pm 0.16$ & $2.46 \pm 0.44$ & $3.26 \pm 1.02$ \\
3.0 & $2.30 \pm 0.31$ & $3.0 \pm 0.5$ & $3.12 \pm 0.56$ & $2.76 \pm 0.46$ \\
10.0 & $4.32 \pm 1.02$ & $4.32 \pm 0.79$ & $4.18 \pm 0.99$ & $5.06 \pm 1.14$ \\
30.0 & $5.70 \pm 1.26$ & $5.78 \pm 1.19$ & $5.76 \pm 1.28$ & $5.80 \pm 1.54$ \\
\hline
\end{tabular}


Table 3. Effect of Saline on 5-Carboxyamidotryptamine (5-CT)-induced Increase in Intragastric, Intraduodenal, and Intracolonic Pressures $\left(\mathrm{cm} \mathrm{H}_{2} \mathrm{O}\right)$ in Bilaterally Vagotomized Spinal Rats

\begin{tabular}{|c|c|c|c|c|}
\hline \multirow[b]{2}{*}{ 5-CT ( $\mu \mathrm{g} / \mathrm{kg}$ i.v. $)$} & \multirow[b]{2}{*}{ Control } & \multicolumn{3}{|c|}{ Saline (ml/kg i.v.) } \\
\hline & & 0.5 & 1.0 & 2.0 \\
\hline & Intragastric & Pressure & $\left(\mathrm{cm} \mathrm{H}_{2} \mathrm{O}\right)$ & \\
\hline 25 & $2.33 \pm 1.2$ & $1.6 \pm 0.4$ & $1.50 \pm 0.3$ & $1.50 \pm 0.42$ \\
\hline 50 & $2.65 \pm 0.45$ & $2.0 \pm 0.32$ & $2.52 \pm 0.49$ & $2.50 \pm 0.4$ \\
\hline \multirow[t]{2}{*}{100} & $3.30 \pm 0.47$ & $2.7 \pm 0.40$ & $3.40 \pm 0.47$ & $3.42 \pm 0.47$ \\
\hline & Intraduodenal & Pressure & $\left(\mathrm{cmH}_{2} \mathrm{O}\right)$ & \\
\hline 25 & $0.95 \pm 0.10$ & $1.0+0.12$ & $0.98+0.10$ & $1.02 \pm 0.10$ \\
\hline 50 & $1.12 \pm 0.13$ & $1.3 \pm 0.20$ & $1.10 \pm 0.20$ & $1.30 \pm 0.20$ \\
\hline \multirow[t]{2}{*}{100} & $1.98 \pm 0.20$ & $1.8 \pm 0.20$ & $2.02 \pm 0.30$ & $1.92 \pm 0.12$ \\
\hline & Intracolonic & Pressure & $\left(\mathrm{cmH}_{2} \mathrm{O}\right)$ & \\
\hline 25 & $1.53 \pm 0.18$ & $1.62 \pm 0.18$ & $1.30 \pm 0.30$ & $1.40 \pm 0.30$ \\
\hline 50 & $1.70 \pm 0.23$ & $1.82 \pm 0.30$ & $1.60 \pm 0.25$ & $1.80 \pm 0.24$ \\
\hline 100 & $3.03 \pm 0.55$ & $3.32 \pm 0.51$ & $3.27 \pm 0.56$ & $3.28 \pm 0.62$ \\
\hline
\end{tabular}

Methiothepin (a known 5- $\mathrm{HT}_{1}$ and $5-\mathrm{HT}_{2}$ receptor antagonist) given prior to 5-HT showed a dose-dependent decrease of the 5-HT pressure response of IGP, IDP, and ICP at doses between 0.1 and $0.5 \mathrm{mg} / \mathrm{kg}$ methiothepin. Furthermore after methiothepin pretreatment, the 5-HT dose dependency was less prominent; higher doses of 5-HT had no superior effect to lower doses The same result was achieved when the 5-HT agonists 5-CT and 5-MT were given after pretreatment with methiothepin (Figures 2, 3, and 4).

Carbachol $(0.5 \mu \mathrm{g} / \mathrm{kg})$ had a strong IGP-increasing effect (higher than the one of $10 \mu \mathrm{g} / \mathrm{kg} \mathrm{5-HT),} \mathrm{while}$ in the colon (ICP), the effect is still strong but when compared to 5-HT, it is much weaker and in the order of $2.5 \mu \mathrm{g} / \mathrm{kg} \mathrm{5-HT}$. Pretreatment of atropine had no significant effect on the 5-HT pressure response in neither the stomach nor the colon, but at all dose lcvels, there was a significant effect on the carbachol-induced pressure response. Interestingly enough, the atropine inhibition of the carbachol-induced pressure increase is much stronger in the IGP where the primary carbachol effect is the highest and much less in the colon. In the colon, full inhibition of the carbachol response only occurs at such high doses as $2.0 \mu \mathrm{g} / \mathrm{kg}$ atropine (Figures 5 and 6). IDP did not show any significant changes.

Histamine $(25,50$, and $100 \mu \mathrm{g} / \mathrm{kg})$ significantly increased IGP without a significant dose relationship; a ceiling effect was already reached with $25 \mu \mathrm{g} / \mathrm{kg}$ histamine. Pretreatment with mepyramine $(0.1,0.3,1.0$, and $3.0 \mathrm{mg} / \mathrm{kg}$ i.v.) slightly inhibited the high-dose histamine response but not the low-dose response if $1.0 \mathrm{mg} /$ $\mathrm{kg}$ was not exceeded. At $3.0 \mathrm{mg} / \mathrm{kg}$ a significant decrease of the histamine pressure response was seen (Figure 7).

The effects of prazosin and domperidone on the gas- trointestinal pressure changes due to dopamine and noradrenaline (Figures 8, 9, and 10) showed, on the one hand, that whereas domperidone had an antagonistic effect to dopamine, it had no effect on the noradrenaline pressure response; this is also true for the arterial pressure responses. On the other hand, prazosin only showed effects when applied prior to noradrenaline, it showed no effect on dopamine responses.

Dopamine (20, 40, and $80 \mu \mathrm{g} / \mathrm{kg}$ ), (Figures 8 and 9) was followed by a dose-dependent decrease of IGP and a dose-dependent increase of IDP and ICP with a concomitant increase in mean arterial pressure. Prior application of domperidone $(0.1,0.3,0.5$, and $1.0 \mathrm{mg} /$ $\mathrm{kg}$ ) had a significant effect on the dopamine-induced pressure decrease in IGP which was dose dependent and was nearly blocked at dosages of $1.0 \mathrm{mg} / \mathrm{kg}$ in the $20-$ and $40-\mu \mathrm{g} / \mathrm{kg}$ dopamine groups, but not fully antagonized when $1.0 \mathrm{mg} / \mathrm{kg}$ domperidone was given versus $80 \mu \mathrm{g} / \mathrm{kg}$ dopamine.

Concerning the dopamine-induced IDP increases, small dosages of domperidone $(0.1$ and $0.3 \mathrm{mg} / \mathrm{kg})$ seem to have a synergistic effect rather than an inhibitory, whereas higher dosages $(0.5$ and $1.0 \mathrm{mg} / \mathrm{kg})$ significantly reduced the pressure-increasing effect of dopamine.

In the colon, domperidone had significant inhibitory effects on the dopamine response except when low doses of dopamine $(20 \mu \mathrm{g} / \mathrm{kg})$ were combined with low doses of domperidone $(0.1 \mathrm{mg} / \mathrm{kg})$.

In comparison to the effects of domperidone in relation to dopamine-induced pressure changes in the gastrointestinal tract, domperidone seems to be much less effective in blocking the arterial pressure increase due to dopamine, with high doses needed to initiate significant changes in response. 

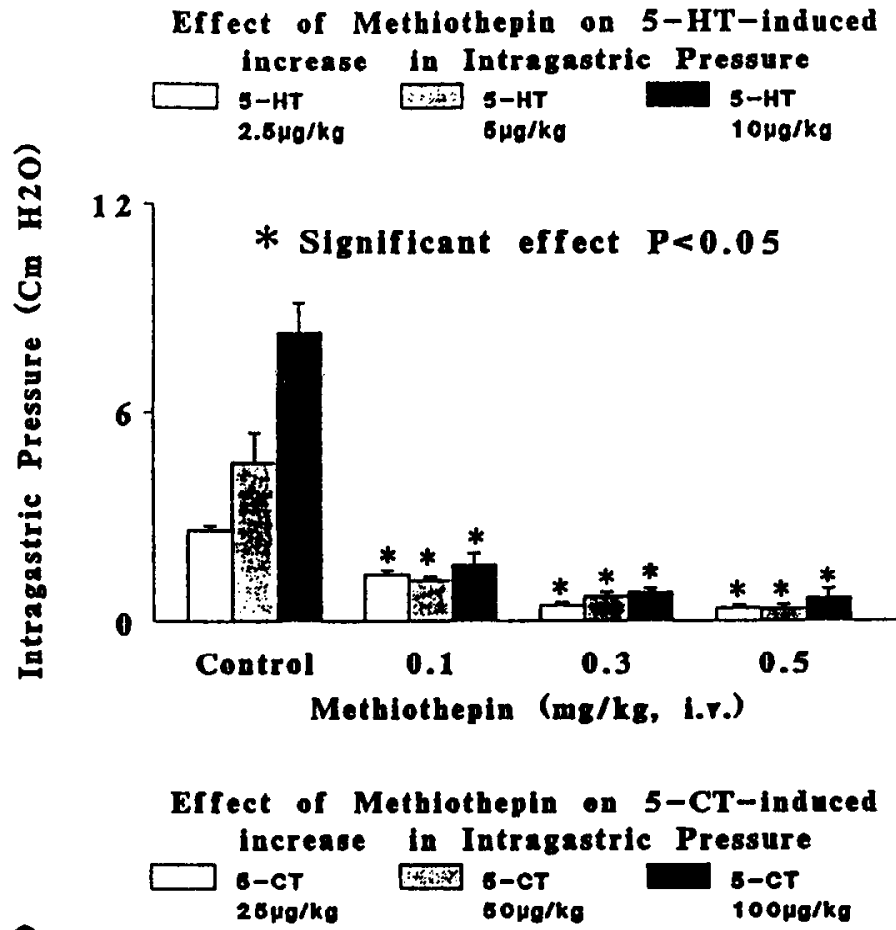

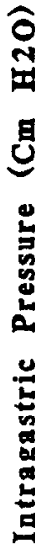

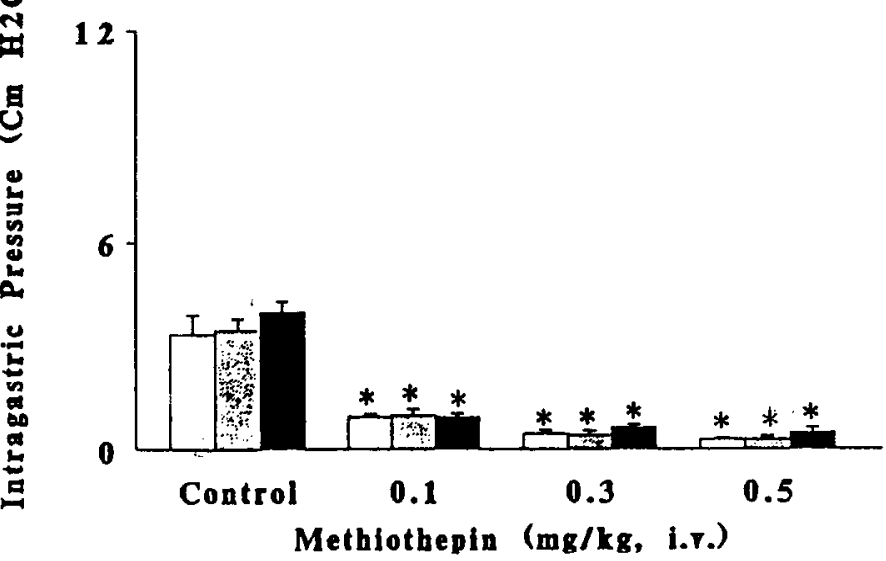

Effect of Methiethepin on 5-MT-indeced Increawe in Intragastric Preasure

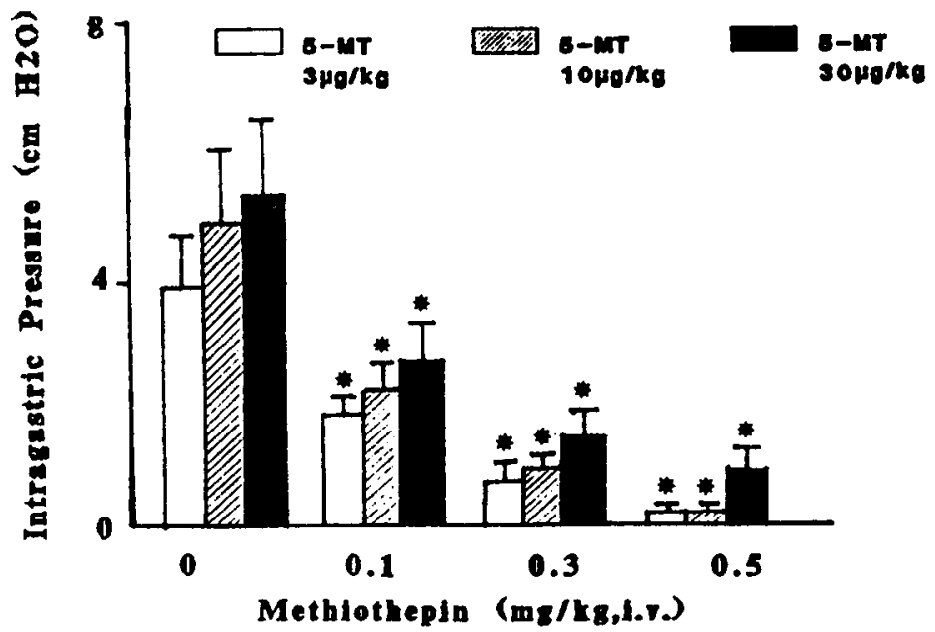

Figure 2. Effect of methiothepin $(0.1,0.3$, and $0.5 \mathrm{mg} /$ $\mathrm{kg}$ i.v.) on the increase in IGP induced by 5-HT (2.5, 5.0 , and $10 \mu \mathrm{g} / \mathrm{kg}$ i.v. ), 5-CT (25, 50, and $100 \mu \mathrm{g} / \mathrm{kg}$ i.v.) or $5-\mathrm{MT}(3,10$, and $30 \mu \mathrm{g} / \mathrm{kg}$ i.v.) in vagotomized spinal rats. 

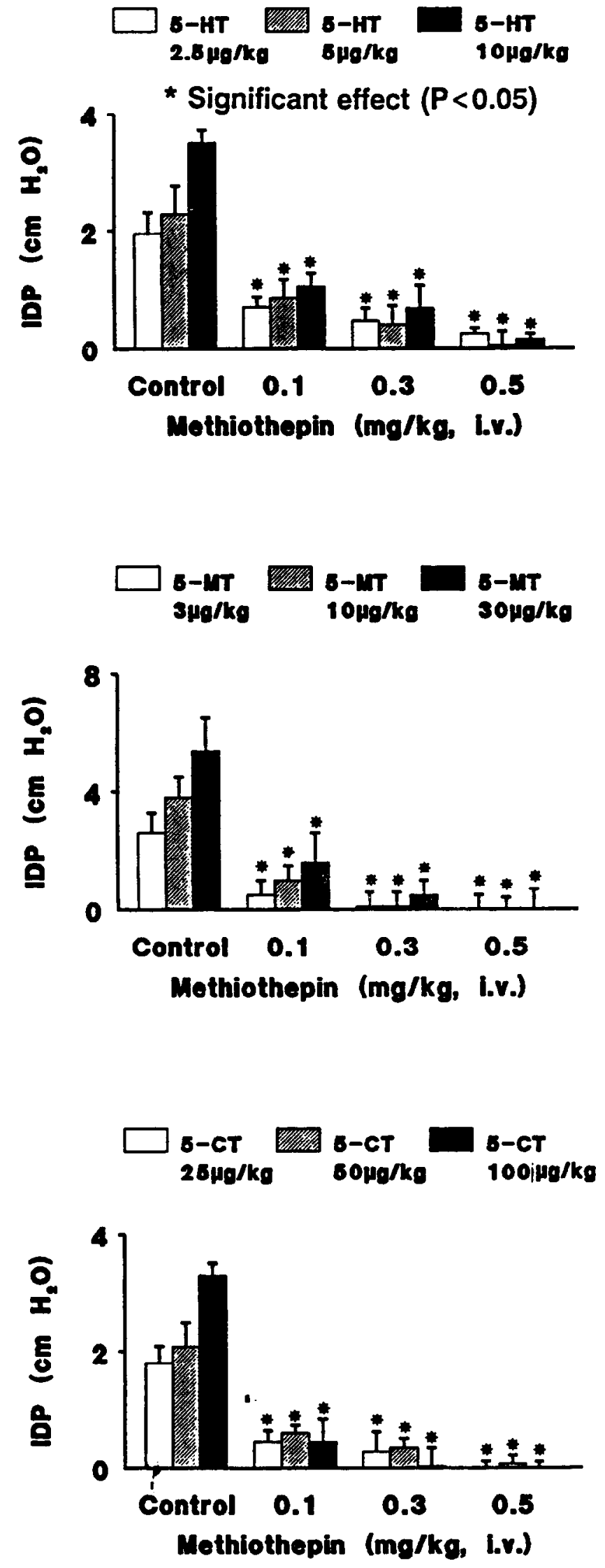

Noradrenaline led to a decrease in intragastric pressure and an increase in intraduodenal and intracolonic pressure (Figure 10). The noradrenaline responses to doses of 1,3 , and $5 \mu \mathrm{g} / \mathrm{kg}$ i.v. were as expected concerning the blood pressure with dose-dependent increases. Prazosin had an inhibitory effect already in low doses $(0.1 \mathrm{mg} / \mathrm{kg})$, but even doses $(0.5 \mathrm{mg} / \mathrm{kg}) \mathrm{did}$ not block the blood pressure response totally.

In contradiction to this, the dose-dependent IGP pressure (Figure 10) decreased following noreadrenaline alone $(1,3$, and $5 \mu \mathrm{g} / \mathrm{kg})$ which was significantly counteracted by prazosin, and dose dependent in all dosage groups $(0.1,0.3$, and $0.5 \mathrm{mg} / \mathrm{kg})$.

Although the ICP pressure increases after noradrenaline were very much and highly significantly reduced in the colon by prazosin, the effect of prazosin on noradrenaline-increased IDP was so strong that pressures were even reduced below the base line values. Interestingly enough, this even occurred in the highest dose group of noradrenaline $(5 \mu \mathrm{g} / \mathrm{kg})$ pretreated by the lowest dose group of prazosin $(0.1 \mathrm{mg} / \mathrm{kg})$. An increase in the prazosin dosage did not seem to have a greater effect in the duodenum, a phenomenon which was also seen in the colon but not in the stomach (Figure 11).

In conclusion, on the one hand, domperidone failed to influence the effect of noradrenaline on IGP, IDP, and ICP. On the other hand, domperidone significantly inhibited the dopamine-induced IGP, IDP, and ICP. Prazosin only reversed the increase of IGP and IDP produced by noradrenaline but not that of ICP.

\section{Discussion \\ Methodological Consideration}

There is not only a central and/or peripheral nervous control of the alimentary canal but also hormones (Chiba et al., 1989) that, for example, can influence the function of gastrointestinal motility, propulsion, ion transport, and blood and oxygen supply. Most of previous studies considering the impact of drugs on gastrointestinal receptors concentrated on the role of different transmitters in the stomach and intestine and have been extensively investigated in vitro: isolated ileum (Gorich et al., 1982), isolated colon (Fontaine et al., 1984), or isolated rat fundus preparation (Vane, 1957; Frankhuizen and Bonta, 1974; Cohen and Fludzinski, 1987); however, very often it is difficult to correlate the in vitro results with those obtained from in vivo studies using the oral charcoal method for studies of the intestinal transit (Green, 1959; Dhasmana et al.,

Figure 3. Effect of methiothepin $(0.1,0.3$, and $0.5 \mathrm{mg} / \mathrm{kg}$ i.v.) on the increase in IDP induced by 5-HT (2.5, 5.0, and $10 \mu \mathrm{g} /$ $\mathrm{kg}$ i.v. $), 5$-CT $(2.5,50$, and $100 \mu \mathrm{g} / \mathrm{kg}$ i.v.) or 5-MT $(3,10$, and $30 \mu \mathrm{g} / \mathrm{kg}$ i.v.) in vagotomized spinal rats. 

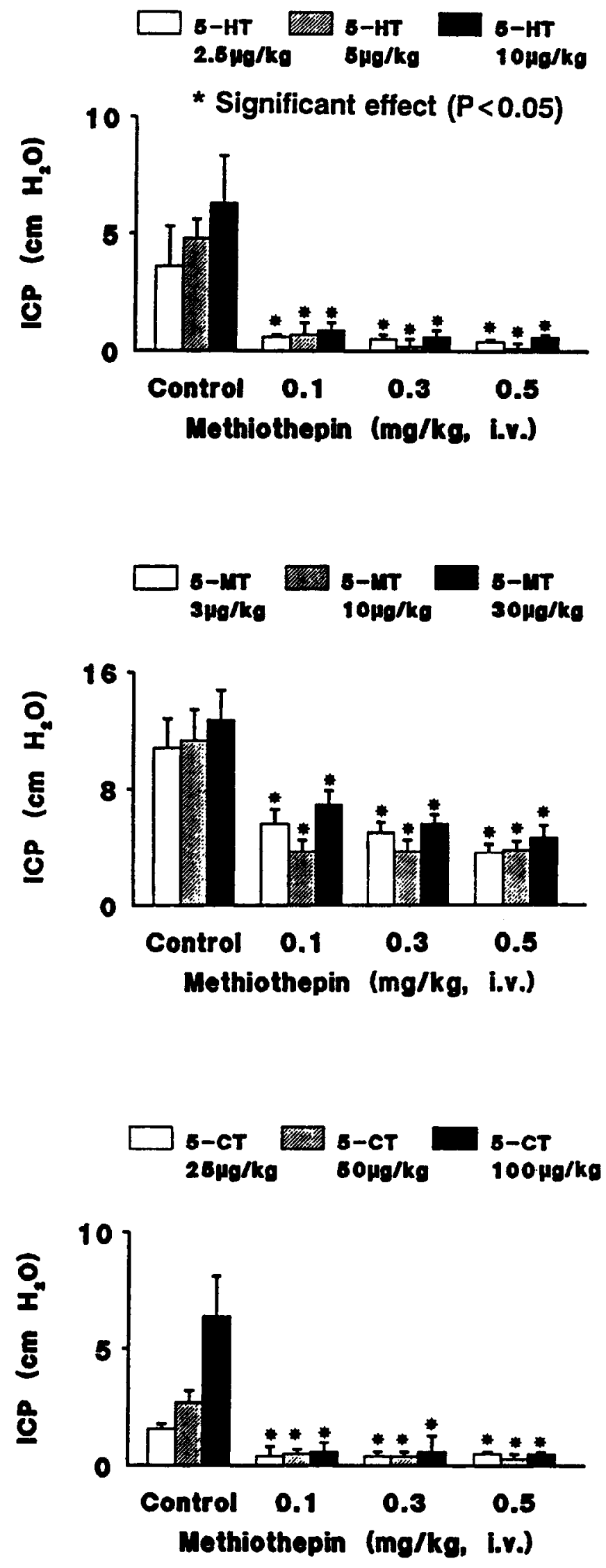

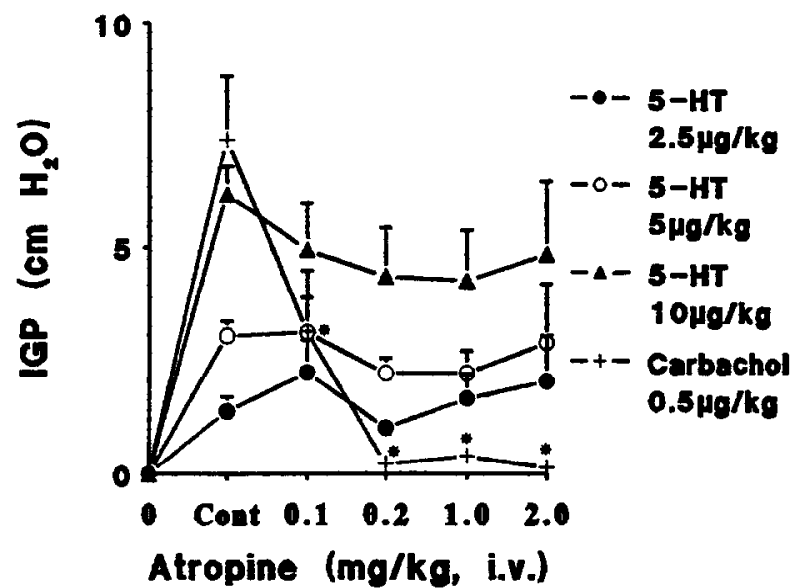

Figure 5. Effect of atropine $(0.1,0.2,1.0$, and $2.0 \mathrm{mg} / \mathrm{kg} \mathrm{i.v.)}$ on the increase in IGP induced by 5-HT $(2.5,5.0$, and $10 \mu \mathrm{g} /$ $\mathrm{kg}$ i.v.) and carbachol $(0.5 \mu \mathrm{g} / \mathrm{kg}$ i.v. $)$ in bilaterally vagotomized spinal rats.

1986, 1987) and the application of radioactive chromium (Miller et al., 1981) or electromyographic registrations for recording of the gastrointestinal motility (Bueno and Ferre, 1982). However, in the described model pressure transducers are used for the registration of intragastrointestinal pressures produced by the contraction of the muscles around a pouch. The pouch reduces in volume by the muscular contraction thus

Figure 6. Effect of atropine $(0.1,0.2,1.0$, and $2.0 \mathrm{mg} / \mathrm{kg} \mathrm{i.v.)}$ on the increase in ICP induced by 5-HT $(2.5,5.0$, and $10 \mu \mathrm{g} /$ $\mathrm{kg} \mathrm{i.v.)} \mathrm{and} \mathrm{carbachol}(0.5 \mu \mathrm{g} / \mathrm{kg} \mathrm{i.v.)}$ in bilaterally vagotomized spinal rats.

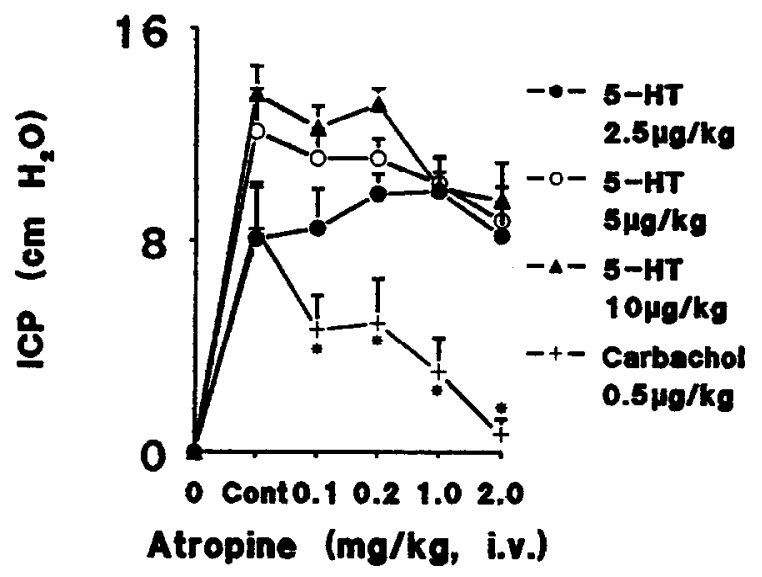

Figure 4. Effect of methiothepin $(0.1,0.3$, and $0.5 \mathrm{mg} / \mathrm{kg}$ i.v. $)$ on the increase in ICP induced by 5 -HT $(2.5,5.0$, and $10 \mu \mathrm{g} /$ $\mathrm{kg}$ i.v.), 5-CT $(25,50$, and $100 \mu \mathrm{g} / \mathrm{kg}$ i.v. $)$ or 5-MT $(3,10$, and $30 \mu \mathrm{g} / \mathrm{kg}$ i.v.) in vagotomized spinal rats. 


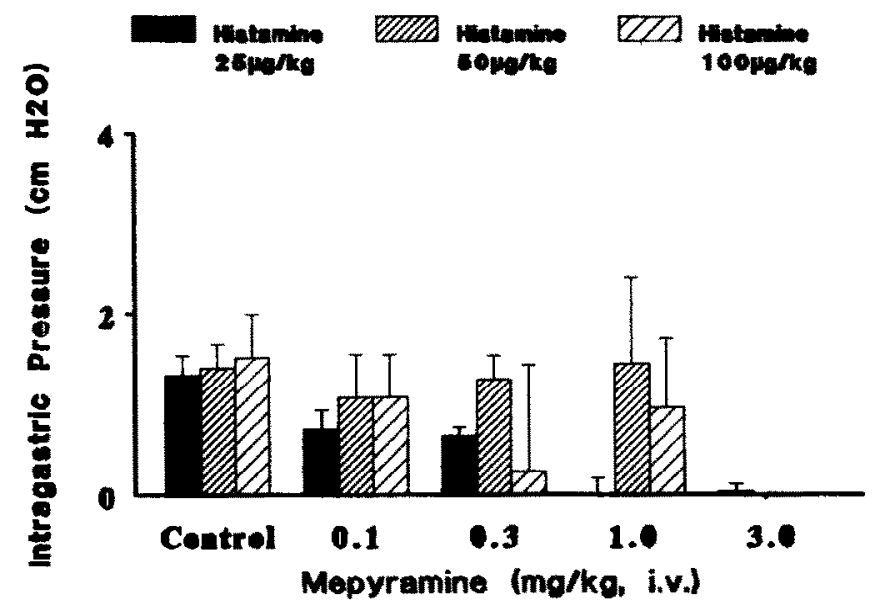

Figure 7. Effect of mepyramide $(0.1,0.3,1.0$, and $3.0 \mathrm{mg} /$ $\mathrm{kg}$ i.v.) on the increase in IGP induced by histamine $(25,50$, and $100 \mu \mathrm{g} / \mathrm{kg} \mathrm{i.v.)}$ in bilaterally vagotomized spinal rats.

forcing the physiological saline into the catheters. The resulting intragastrointestinal pressure is continuously measured through Statham transducers; and the Grass Model 70 Polygraph amplified values are recorded. The registered changes in IGP, IDP, and ICP responses provide continuous indirect measurement of drug-induced contraction or relaxation of the gastrointestinal smooth muscles.

Figure 8. Effect of domperidone $(0.1,0.3$, and $0.5 \mathrm{mg} / \mathrm{kg} \mathrm{i.v}$.) on the increase in MAP and decrease in IGP induced by dopamine $(20,40$, and $80 \mu \mathrm{g} / \mathrm{kg} \mathrm{i.v.})$ in bilaterally vagotomized spinal rats.
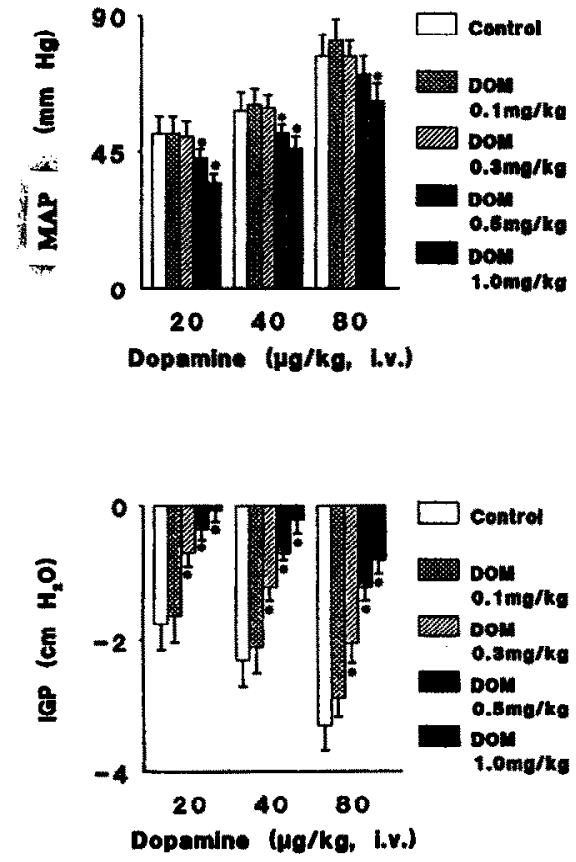
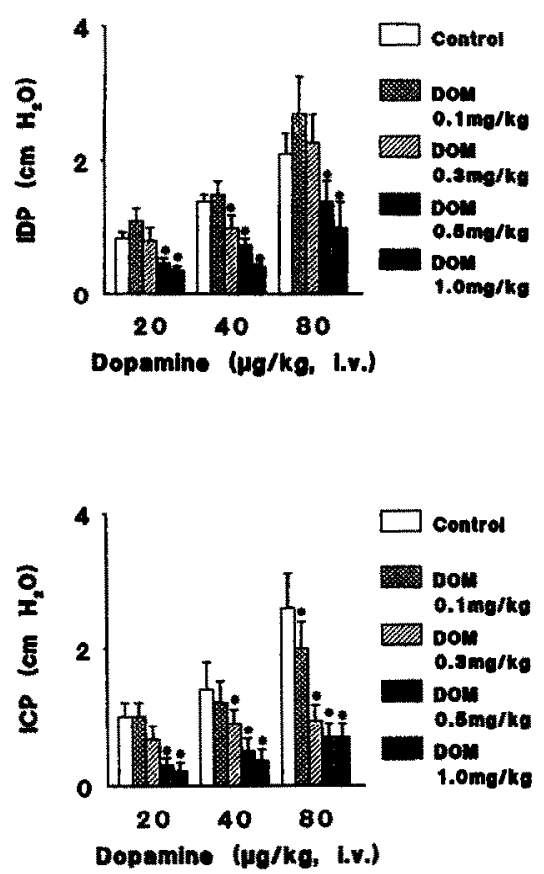

Figure 9. Effect of domperidone (0.1,0.3, and $0.5 \mathrm{mg} / \mathrm{kg} \mathrm{i.v.)}$ on dopamine-induced increase in IDP and ICP in bilaterally vagotomized spinal rats.

Figure 10. Effect of prazosin $(0.1,0.3,1.0$, and $3.0 \mathrm{mg} / \mathrm{kg}$ i.v.) on the increase in MAP and decrease in IGP induced by noradrenaline $(1,3$ and $5 \mu \mathrm{g} / \mathrm{kg} \mathrm{i.v.)}$ in bilaterally vagotomized spinal rats.
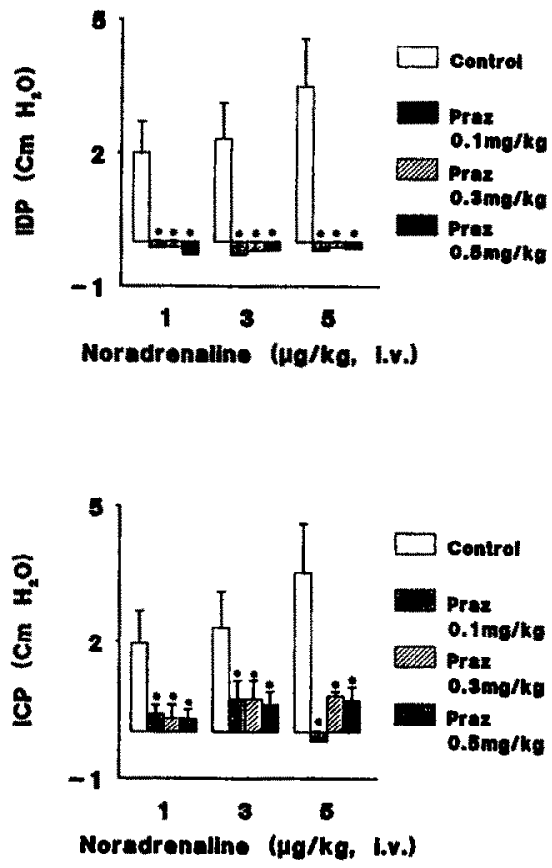

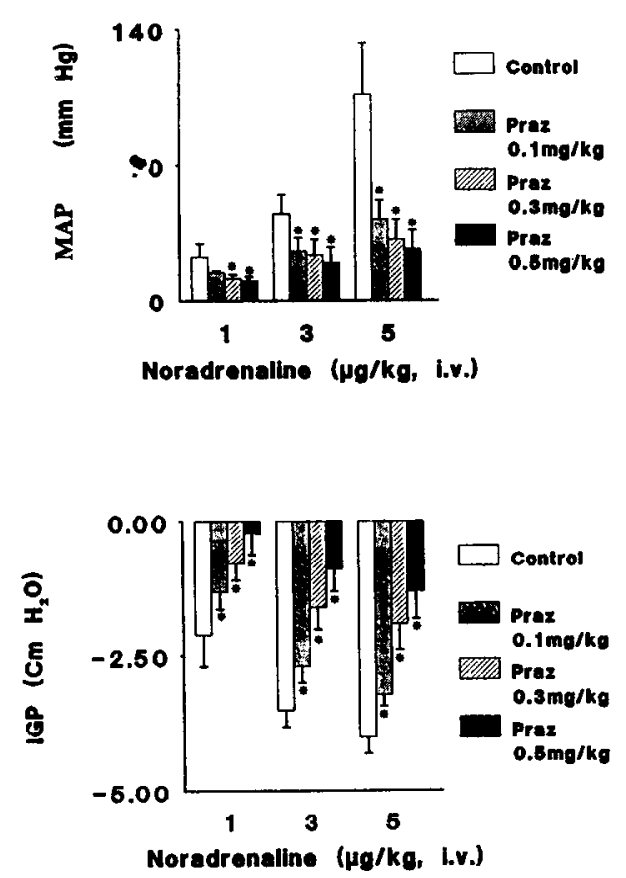

Figure 11. Effect of prazosin $(0.1,0.3,1.0$, and $3.0 \mathrm{mg} / \mathrm{kg}$ i.v.) on the increase in IDP and ICP pressure obtained following administration of noradrenaline $(1,3$, and $5 \mu \mathrm{g} / \mathrm{kg}$ i.v.) in bilaterally vagotomized spinal rats.

\section{Effect of 5-HT and 5-HT-Agonists on IGP, IDP, and ICP}

The present preparation is very sensitive to $5-\mathrm{HT}$ $(2.5-10 \mu \mathrm{g} / \mathrm{kg}), 5-\mathrm{MT}(3-30 \mu \mathrm{g} / \mathrm{kg})$, and higher doses of 5-CT $(25-100 \mu \mathrm{g} / \mathrm{kg})$. These effects of 5-HT and 5HT-agonists are antagonized by prior administration of methiothepin $(0.1,0.3$, and $0.5 \mathrm{mg} / \mathrm{kg}$, i.v.). Taking into consideration that 5 -HT affinity is higher for 5$\mathrm{HT}_{1}$ than 5- $\mathrm{HT}_{2}$ receptors (Bradley et al., 1986), it may be conceived that the increase in IGP, IDP, and ICP

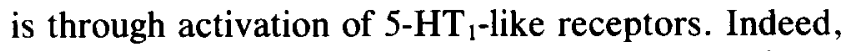
this is in agreement with our findings reported in an earlier publication (Dhasmana et al., 1992). Methiothepin, furthermore, antagonizes the effect of 5-HT and 5-CT with high affinity to 5- $\mathrm{HT}_{3}$ (duodenum) and $5-\mathrm{HT}_{4}$ (colon) receptors but also antagonizes 5-MT with high affinity to only $5-\mathrm{HT}_{4}$ receptors present in the colon where 5- $\mathrm{HT}_{3}$ receptors are not present (Saxena and Villalon, 1990). On the other hand application of 2-methyl-5-HT with a higher affinity for $5-\mathrm{HT}_{3}$ receptors (Saxena and Villalon, 1990) also led to an increase of IGP, IDP, and ICP responses. The pressor responses induced by 2-methyl-5-HT in the duodenum was significantly inhibited by its antagonist tropisetron which antagonized the IGP responses of 2-methyl-5$\mathrm{HT}$ only in the lower dose ( 25 and $50 \mu \mathrm{g} / \mathrm{kg}$ ) range. However, tropisetron did not influence the 2-methyl-
5-HT-induced increase in ICP. Thus these results show that $5-\mathrm{HT}_{3}$ receptors are involved in IGP and IDP and $5-\mathrm{HT}_{4}$ receptors are involved in ICP.

\section{Effect of Atropine and Mepyramine on Carbachol and the Histamine-induced Increase in IGP}

Carbachol produces an increase in IGP and a similar effect was also observed with 5-HT. However, atropine significantly inhibited the carbachol-induced increase of IGP without influencing 5-HT-induced increase of IGP. Likewise, histamine also significantly increased IGP which was significantly antagonized by prior administration of mepyramine in a dose-dependent manner. This leads to the conclusion that atropine inhibits the carbachol-induced increase of IGP through $\mathrm{M}_{2}$-receptor, and mepyramine inhibits the histamineinduced increase of IGP through H-receptors, but not through 5-HT-receptors.

\section{Effect of Prazosin and Domperidone on Noradrenaline and Dopamine-Induced Decrease in IGP and Increase in IDP and ICP}

It is now well recognized that dopamine is a neurotransmitter, present in significant amounts in the alimentary canal (Gaudin et al., 1985), and probably plays a modulating role in the intestinal motility (Dhasmana et al., 1989). In the present investigation, noradrenaline and dopamine alike also decreased IGP in a dose-dependent manner but both also simultaneously increased IDP and ICP. Nevertheless, prazosin antagonized the inhibitory effects of noradrenaline and dopamine on IGP, whereas domperidone failed to influence the noradrenaline-induced decrease in IGP, although it significantly inhibited the dopamine-induced decrease in IGP as well as the dopamine-induced increase in IDP and ICP. This leads to the conclusion that the paradoxical effect of dopamine is based on $D_{2}$-dopamine and $\alpha_{1}$-adrenergic receptors and that of noradrenaline is only due to $\alpha_{1}$-adrenergic receptors.

\section{Advantage of the Described Model}

The results and interpretation described above clearly demonstrate the impact and advantages of the developed methodological model to interpret the complicated interaction of the gastrointestinal motility receptor scheme: 1) It is a simple, reliable, reproducible, and appropriate model for the studies of different receptors in the gastrointestinal system. Time of surgical preparation is only $35 \pm 5 \mathrm{~min}$, the rate of experimental success is up to $98 \%$, and tachyphylaxis after repeated 
administration is missing; 2 ) It shows a highly sensitive response behavior to, for example, 5-HT, 5-HT-agonists, and -antagonists, carbachol, histamine, dopamine, and/or noradrenaline. One of the most remarkable features of response is the rapid onset of the effect, and the peak pressure being reached within $30 \mathrm{sec}$, while the effect only lasts $5-7 \mathrm{~min}$ with a rapid return to baseline values in less than $10 \mathrm{~min}$. Thus it is possible to study 1) cholinergic receptors which moderate muscular tone, amplitude of contractions, and peristaltic activity. Cholinergic drugs may be useful in gastroesophageal reflex syndromes (e.g., carbachol and bethanechol). They are active in this condition and increase peristaltic activity as well; 2) muscarinic antagonists (scopolamine butylbromide ( $\mathbf{M}_{2}$ antagonist: e.g., atropine, cimetropium bromide) are beneficial as antispasmodic agents and for the irritable bowel syndrome; 3) adrenergic receptors: $\alpha_{2}$-adrenergic receptor agonists such as antidiarrheal agents (clonidine) prolong the intestinal transit time. The adrencrgic system may be involved in water and electrolyte transport; 4) dopamine: dopamine antagonists, for example, domperidone and metoclopramide are used as gastrokinetics and for the irritable bowel syndrome; 5) 5-HT and 5HT-agonists and -antagonists: cisapride (5-HT-agonist) is used as a gastrointestinal motility stimulant in the postoperative phase in paralytic ileus. $5-\mathrm{HT}_{3}$-antagonists (granisetron, ondansetron, zacopride, tropisetron, renzapride), some of which are progastrokinetic and others have been found to be effective as agents to prevent vomiting, are used in patients undergoing chemotherapy and radiotherapy for cancer; 6) opiates: morphine and morphinomimetic drugs are useful in diarrhea (loperamide). 7) calcium antagonists, for example, verapamil or nifedipine, may be useful in diarrhea, gastric ulcer, and irritable bowel syndrome.

The list of drugs pertaining to this topic could be much further expanded, and all of which could be investigated and compared simultaneously for their effects on the motility of the stomach, duodenum, and colon. Furthermore, as shown above, the method is useful when 1) investigating paradoxical effects of drugs and 2) differentiating their mode of action. The one of dopamine through $D_{2}$-dopamine and $\alpha_{1}$-adrenergic receptors and that of noradrenaline through $\alpha_{1}$-adrenergic receptors only. Due to vagatomy and decerebration (rat anencephalé), the influence of the vagus and central nervous system on the gastrointestinal system-which could modify the effect of the investigating drugs (Pagani et al., 1985) - is fully avoided. Thus this model provides superb and unspoiled information on the interaction of the investigated drugs with the receptors located in the gastrointestinal smooth muscles, this before and after antagonist application or saline.
The gastric motility and secretion in the anesthetized rats could be studied atso with the intact vagus, before vagotomy is performed, thus offering an appropriate method to study the systemic effects of drugs on the intragastric pressure and secretion (Andrews and Wood, 1986) and thereafter, after vagotomy, to consider the local effects only. Nevertheless, the electrical stimulation of different centers in the central nervous system revealed a profound influence of the gastrointestinal tract through parasympathetic and sympathetic outflows (Andrews and Wood, 1986). In addition, the centrally administered neurotransmitters (5-hydroxytryptamine, Bugjaski et al., 1977; cholecystokinin, Ishikawa et al., 1985; and calcitonin, Morley et al., 1981) have shown to influence the gastrointestinal system. Hence, in order to circumvent central and vagal influence on the gastrointestinal system, we have developed this technique of continued vagotomy and decerebration which makes it possible to explore the role of different receptors on the gastrointestinal muscles without systemic influence.

\section{Disadvantage of the Described Model}

Some disadvantages must be reported. 1) It is not possible to predict whether drugs increase or decrease the gastrointestinal emptying rate since increasing motility does not always occur proportionally with the enhanced emptying (Andrews and Wood, 1986). To avoid this investigational gap, we note that gastrointestinal transit was studied by oral charcoal (Dhasmana et al., 1987). 2) It is not possible to measure the increase or decrease in $\mathrm{pH}$ of the gastric, duodenal, pancreatic, and colonic secretions as well as ion transport.

\section{Avoidance of Methodological Pitfalls}

In order to maintain unchanged sensitivity and reach a high success ratio, we note the operation must be performed with extreme caution: 1) The blood supply to the intestine must never be disturbed, and the gastrointestinal wall must not be injured. It has been shown that sensitivity of the gastrointestinal system to drugs is decreased proportionally to the amount of gastrointestinal damage. 2) Spinal section and both sides vagus nerve dissection should be absolutely complete. 3) Time has to be allowed (1 hr) for stabilization of the physiological (base line) parameters after operation. 4) The duodenum and colon must be cleaned carefully by flushing it with saline, thus making it free of fecal material.

The present work was supported by The Dutch Foundation of Fundamental Research (SFMO). 


\section{References}

Andrews PLR, Wood KL (1986) Systemic baclofen stimulates gastric motility and secretion via a central action in the rat. $B r J$ Pharmacol 89:461-467.

Bueno L, Ferre J (1982) Central regulation of intestinal motility: somatostatin and cholecystokinin octapeptide. Science 216: $1427-1429$.

Bradley BP, Engel G, Feniuk W, Humphrey PPA, Middlemiss DN, Mylecharane EJ, Richardson BP, Saxena PR (1986) Proposals for the classification and nomenclature of functional receptors for 5-hydroxytryptamine. Neuropharmacology 25:563-576.

Bugajski J, Hano J, Danek L, Wantuch C (1977) The action of serotonin basal gastric secretion in the conscious rat after intraventricular and intraperitoneal administration. Archives Int Pharmacodyn 225:29-38.

Chiba T, Park J, Yamada T (1989) Calcitonin gene related peptide (CGRP) stimulates somatostatin secretion from isolated gastric D-cells via cyclic AMP dependent mechanisms. Gastroenterology 96:A86.

Cohen ML, Fludzinski LA (1987) Contractile serotonergic receptor in the rat stomach fundus. J Pharmacol Exp Ther 243:264-269.

Frankhuizen AL, Bonta IL (1974) Receptors involved in the action of 5-HT and tryptamine on isolated rat stomach fundus preparation. Eur J Pharmacol 26:220-230.

Dhasmana KM, Banerjee AK, Erdmann W (1987) Gastrointestinal transit following intrathecal or subcutaneous narcotic analgesics. Archiv Int Pharmacodyn 286:152-160.

Dhasmana KM, Banerjee AK, Faithfull NS, Erdmann W (1986) Role of 5-hydroxytryptamine receptors in narcotic-induced reduction in gastrointestinal transit in rats. Acta Pharmacol Sinica 7: 499-504.

Dhasmana KM, Banerjee AK, Zhu YN, Erdmann W, Parmar SS, Salzman $S$ (1989) Role of dopamine receptors in gastrointestinal motility. Res Commun Chem Pathol Pharmacol 64:485-489.

Dhasmana KM, Villalon CS, Zhu YN, Tadipatri S, Saxena PR (1992) Role of $5-\mathrm{HT}_{1}$-like receptors in the increase in intragastric pres- sure induced by 5-hydroxytryptamine in the rat. Eur J Pharmacol 212:293-299.

Fontaine J, Grivegnee A, Reuse J (1984) Adrenoceptors and regulation of intestinal tone in the isolated colon of the mouse. $\mathrm{Br} J$ Pharmacol 81:231-243.

Gaudin C, Ruget G, Selz F, Cuch JL (1985) Free and conjugated catecholamine in digestive tissues of rats. Life Sci 37:1469-1474.

Gershon MD, Erde SM (1981) The nervous system of the gut. Gastroenterology 80:1571-1594.

Gorich R, Weihrauch TR, Kilbingen H (1982) The inhibition of dopamine of cholinergic transmission in the isolated guinea-pig ileum. Naunyn-Schmiedeberg's Arch Pharmacol 318:308-312.

Green AF (1959) Comparative effects of analgesic drugs on pain threshold, respiratory frequency and gastrointestinal propulsion. Br J Pharmacol Chemother 14:26-34.

Ishikawa T, Osumi T, Nakagawa Y (1985) Colecystokinin intracerebroventricularly applied stimulates gastric acid secretion. Brain Res 333:197-199.

Miller MS, Galligan JJ, Burks TF (1981) An evaluation of methods for measurement of intestinal transit. J Pharmacol Method 6: 211-217.

Morley JE, Levine AS, Silvis SE (1981) Intraventricular calcitonin inhibits gastric acid secretion. Science 214:671-673.

Orloff LA, Orloff MS, Bunnett NW, Walsh JH (1985) Dopamine and norepinephrine in the alimentary tract: Changes after chemical sympathectomy and surgical vagotomy. Life Sci 36:1625-1631.

Pagani FD, Norman WP, Kasbekar DK, Gillis RA (1985) Localization of sites within the dorsal motor nucleus vagus that effect gastric motility. Am J Physiol 249:G73-84.

Saxena PR (1985) An interactive computer program for data management and parametric and non-parametric statistical analysis. $\mathrm{Br}$ $J$ Pharmacol 86:818P.

Saxena PR, Villalon CM (1990) Cardiovascular effects of serotonin agonists and antagonists. J Cardiovasc Pharmacol 15:(Suppl 7)S17-S34.

Vane JR (1957) A sensitive method for assay of 5-HT. Br J Pharmacol 12:344-352. 